\title{
Eficacia de los sitios webs como herramienta comunicacional de los Diputados chilenos.
}

\author{
Efficacy of websites as a communication tool for Chilean deputies.
}

\author{
Fuente-Alba Cariola, F. y Parada Gavilán, C. ${ }^{1}$ \\ Recibido: 05-04-2019 - Aceptado: 27-07-2019 \\ DOI: https://doi.org/10.26441/RC18.2-2019-A7
}

\begin{abstract}
RESUMEN: Este artículo estudia la eficacia de los sitios webs de Diputados chilenos como herramienta comunicacional. Los investigadores realizan un análisis de contenido a la totalidad de webs de parlamentarios en dos momentos: 2015 y 2018. Un primer dato es que sólo la mitad de los Diputados tiene sitio web, desechando su potencial como herramienta de comunicación con los ciudadanos. Además, ninguna de las 129 webs analizadas, 66 el 2015 y 63 el 2018, es eficaz en términos de comunicación digital, subutilizando el potencial informativo y dialogante de esta herramienta. El artículo también entrega datos en torno al uso de Facebook y Twitter por los parlamentarios. A la luz de los resultados, los webs y plataformas sociales de Diputados chilenos son utilizados en la lógica antigua de la comunicación de masas que contempla un emisor y un público pasivo, contradiciendo la democratización digital que caracterizan la comunicación del siglo XXI.
\end{abstract}

Palabras claves: sitios webs; internet; ciberdemocracia; comunicación digital.

\begin{abstract}
This article studies the effectiveness of websites of Chilean deputies as a communication tool. Researchers conduct a content analysis of the entire website of parliamentarians at two moments: 2015 and 2018. A first fact is that only half of the deputies have a website, rejecting its potential as a communication tool for citizens. In addition, none of the 129 websites analyzed, 66 in 2015 and 63 in 2018 , is effective in terms of digital communication, underutilizing the informative and dialogical potential of this tool. The article also provides information about the use of Facebook and Twitter by parliamentarians. In the light of the results, the websites of Chilean deputies are used in the old logic of mass communication that includes a sender and a passive public, contradicting the digital democratization that characterizes the communication of the 21 st century.
\end{abstract}

Keywords: websites; internet; cyberdemocracy; digital communication.

\footnotetext{
${ }^{1}$ Fernando Fuente-Alba Cariola es Doctor en Comunicación Audiovisual por la Universidad Complutense de Madrid y Profesor de Lenguaje Audiovisual y seminarios de investigación en nuevas tecnologías y sociedad en la Facultad de Comunicación, Historia y Ciencias Sociales de la Universidad Católica de la Santísima Concepción. ffuentealba@ucsc.cl, https://orcid.org/0000-0002-4316-5097

Carolina Parada Gavilán es Doctora en Comunicación y Sociología por la Universidad Complutense de Madrid y Profesora de Comunicación Política, Comunicación Estratégica y Pensamiento Político en la Facultad de Comunicación de la Universidad del Desarrollo. cparada@udd.cl, https://orcid.org/0000-0001-9673-9085
} 


\section{Introducción}

La desafección política propia de las democracias occidentales, sumada a la crisis de confianza transversal de las instituciones chilenas, le ha demandado a la clase política mayores niveles de transparencia, interacción y coherencia entre el "ser" y "parecer", en lenguaje aristotélico. Especialmente en un momento donde la ciudadanía está cada vez más vigilante del poder, buscando un ejercicio de coherencia entre lo que es y lo que dice ser.

El proceso de construcción de marca de la clase política, se alimenta por un lado de un contexto social marcado por la desconfianza, el descrédito y la vigilancia ciudadana a las instituciones de poder, incluidos los medios de comunicación, la personalización de la política; y por otro lado de un contexto tecnológico caracterizado por la democratización de la tecnología, la masificación del uso de las redes sociales on line y la instantaneidad de la información (Arriagada y Navia, 2013).

Es en este escenario donde los sitios webs, como nodo de red informativo desde la óptica de la Teoría de Redes, se puede visualizar como un artefacto que aporta a la comunicación de los Diputados chilenos con sus diferentes públicos. Desde esa perspectiva es importante conocer por ejemplo ¿Cuál es el nivel de interacción de los sitios webs?, ¿Qué uso hacen los Diputados chilenos de sus webs como herramienta comunicacional? y si ¿existen estrategias de comunicación digital presentes en las webs de los Diputados chilenos?

Enmarcado en la línea investigativa de análisis de sitios webs del profesor José Luis Dader y su equipo, el presente estudio recoge las cuatro grandes dimensiones: Información, Interactividad, Sencillez de uso y Atractivo Persuasivo, añadiendo la dimensión Redes y adaptando el instrumento a indicadores propios de la realidad chilena. La reflexión se realiza desde el prisma de la Teoría de Redes y busca estudiar la eficacia de los sitios webs de los Diputados chilenos como herramienta comunicacional, mediante un estudio exploratorio-descriptivo. Para ello, se consideró la totalidad de los sitios webs alojados en la red al momento de la investigación y pertenecientes a Diputados del período 2014-2018. La observación se hizo en dos momentos diferentes, considerando la proximidad de las elecciones parlamentarias, finales del 2015 y primeros meses del 2018.

\section{Marco Teórico}

\subsection{Política e Internet en Chile}

Siguiendo la tendencia mundial y latinoamericana, Chile ha experimentado un crecimiento exponencial en su índice de conectividad a Internet. En una década los chilenos conectados pasaron de constituir el $20 \%$ a un $91 \%$, incluido internet fija y móvil (fuente Subtel, informe julio 2017).

El ejercicio de la política no se ha mantenido ajeno a esta tendencia, y desde la campaña presidencial de 1999 a la fecha la presencia de Internet en la comunicación política va en ascenso, registrando algunos peak en periodos de contienda electoral. Sitios webs, blogs y redes sociales han proliferado bajo el discurso de acercamiento entre gobernantes y gobernados. La desafección ciudadana hacia la política no disminuye y por el contrario parece aumentar a la luz de la negativa, principalmente de los jóvenes, de participar en el ejercicio democrático a través del voto. A lo anterior se suma la crisis de legitimidad que vive la política chilena, con 
numerosos casos de corrupción que complican de manera transversal a gobierno y oposición y que tienen como elemento en común la escasa transparencia en el ejercicio de las funciones de líderes de distintos sectores.

Así las cosas, este cuadro de desafección política, justifica la opción de explorar las posibilidades que ofrece la web como herramienta de acercamiento entre elite política y ciudadanía. De hecho, un estudio realizado el 2017 en Chile y España, demuestra que los jóvenes encuestados coincidieron en valorar como positivo el uso de nuevas formas de participación democrática. En este sentido, "los jóvenes estudiantes apoyaron la necesidad de un mayor esfuerzo por hacer partícipe al ciudadano de la vida política, tanto en el terreno online como en el offline" (Sola-Morales y Hernández-Santaolalla, 2017: 648).

¿Por qué diagnosticar la eficacia de los sitios webs de Diputados chilenos como herramienta comunicacional de estrategia política? Por un lado, los escasos estudios que abordan la temática de ciber política chilena lo justifican, pero por otro no menos importante el que la web sea definida como un instrumento para perfeccionar la democracia no deja de ser un reto de investigación, especialmente cuando se busca aprovechar la Red para romper el modelo unidireccional de comunicación, estableciendo la realidad virtual de los legisladores chilenos. Por otro lado, el nivel de conectividad del país es de lo más altos de Latinoamérica, por lo que cabe preguntarse si los representantes en el Parlamento están a la altura de dichas estadísticas y si realmente existen estrategias de comunicación presentes en el diseño y estructura de sus plataformas.

Por último, el voto voluntario vigente en Chile desde el año 2012, obliga a los políticos a utilizar nuevas herramientas de difusión ante sus potenciales votantes. La presencia del parlamentario en perfiles de Facebook y Twitter son un ejemplo de los esfuerzos comunicacionales de los equipos políticos. Cambios sociales influidos por la crisis de confianza y legitimidad de las instituciones, ponen de manifiesto que los políticos no están logrando sintonizar con la ciudadanía a través de las herramientas tradicionales y que necesitan urgentemente ser reconocidos y posicionarse positivamente. En este sentido el sitio web puede representar un aporte relevante si se administra eficazmente.

\subsection{Comunicación política y marketing}

Antonio Caro (2010) lo mencionaba ampliamente, la publicidad omnipresente que construye marcas comerciales y corporativas hoy trasciende al producto y construye personalidades. Es una época donde confluyen "campañas modernas y posmodernas" (Norris, 1997), caracterizada por una crisis de credibilidad de los partidos. Los líderes políticos, merced a una preponderante profesionalización de la asesoría en comunicación, han optado por erigirse en 'marcas' fácilmente identificables, posicionadas y diferenciadas, con su propio espacio en la mente del ciudadano y elector (Pérez Díaz, 2010).

El hecho que determinadas personas, en este caso líderes políticos, sean considerados como una marca no es un planteamiento nuevo. Su discusión inicial surge a finales de los 70 con el marketing político, como un intento de aplicar las estrategias comerciales de la publicidad a la arena política y competitividad electoral (O'Shaughnessy en Uribe, Buzetal \& Reyes, 2017). Desde esta perspectiva todo podría influir en la marca del político. Tanto lo que haga, diga o deje de decir, como su web, twitter, facebook, instagram o whatsapp deben estar alineados para 
conseguir el objetivo estratégico propuesto. De hecho, en las últimas elecciones presidenciales de Estados Unidos, según un estudio de Pew Research Center (18 de julio de 2016), un 44 por ciento de los adultos de Estados Unidos obtuvieron información sobre los candidatos a través de las redes sociales (Williams, 2017).

Existen importantes estudios durante el último lustro que se refieren a la importancia de algunos factores que pueden influir en la construcción de una marca para un político determinado. Recientemente Achor, Nwachukwu y Udensi investigaron empíricamente como la marca política y los rasgos o dimensiones de la personalidad de la marca-candidato, influyen en el voto de los electores. Los resultados muestran que las dimensiones de la personalidad de la marca, (el candidato) como la competencia, la credibilidad, la sinceridad, sofisticación o audacia son atributos que influyen en la elección de los votantes de un candidato político antes y durante la elección (Achor, Nwachukwu y Udensi, 2017).

Habrá que preguntarse entonces, cómo las estrategias de los asesores comunicacionales de los parlamentarios logran volcar en sus sitios webs las directrices correctas para mejorar la imagen de marca de cada diputado y de acuerdo a qué indicadores.

\subsection{La web como estrategia política}

La postura predominante en la esfera de organizaciones políticas es la que considera que el posicionamiento web de una organización es la suma de medidas adoptadas para que los públicos de interés tengan conocimiento on line de su actividad, manejando un conjunto de variables de diseño que aumentan el atractivo de la marca e incitan a su prueba (Chong y Druckman 2007 en Vila- Lopez, 2013).

Ya Vila-López el 2013, mediante un estudio donde encuestó a 217 internautas de web políticas, llegaba a concluir que los aspectos innovadores del sitio del partido político aumentan la calidad percibida del servicio y de paso los del candidato. La prestación de servicios electrónicos, la mejora de la funcionalidad de la web, un diseño atractivo y un mayor grado de información sobre los diferentes servicios, favorecerá el boca oreja entre los diferentes usuarios (Vila-López, 2013).

De esta manera, el internauta a través de las webs de parlamentarios debería tener acceso a ampliar su información respecto a temas como la familia, la seguridad, salud, educación y medio ambiente. Una buena manera es través de links a blogs de especialistas utilizando la conexión con redes sociales. Todo ello, con un importante número de herramientas interactivas como suscripciones, conversaciones virtuales, postcast y la sindicación de contenidos de redes sociales. Así debieran desencadenarse opiniones favorables hacia dicha marca política, sea el partido o el candidato, arrastrando más potenciales votantes y logrando un mayor éxito en las elecciones (Brams y Davis, 1974; Bartels, 1988 en Vila-López et al, 2013).

Sin embargo, a pesar de las ventajas expuestas, el uso de estos recursos digitales sigue siendo muy intuitivo y rara vez responde a una estrategia real por parte del político, aun cuando "se han integrado ciertos reflejos digitales de actividad (sitios webs, fan page, una cuenta de Twitter o un canal de YouTube). No obstante, los usos de estas herramientas son poco transparentes y asociados a asesores especializados privados" (Cárdenas, Ballesteros y Jara, 2017, p.28). 
No es extraño entonces, como dicen Williams \& Gulati (2010) que se considere que los contenidos web sobre política, como las páginas de candidatos, blogs y especialmente las SNS (Social Networking Sites), supongan un nuevo terreno en el que se establece la batalla electoral, a partir de la cercanía y proximidad entre los candidatos y ciudadanos que dichos soportes facilitan (Muniz, Dader et al, 2016). Desde este punto de vista los parlamentarios debieran aprovechar las ventajas de la comunicación digital, especialmente pues "las tecnologías digitales promueven enormes cambios en las prácticas comunicativas y la sociabilidad: donde los públicos locales son limitados, los públicos digitales son, en teoría, ilimitados. Redes sociales como Facebook y Twitter, páginas webs especializadas, blogs y teléfonos inteligentes proveen información y se utilizan como medios para la promoción de acciones de movilización" (Grau, 2016, pp.755-787).

En la vereda contraria, los ciudadanos a través de nuevas tecnologías y mejores mecanismos de control, pueden evaluar el desempeño de sus autoridades de forma activa y regular. De igual forma, las audiencias utilizan las nuevas tecnologías para equilibrar a su favor el balance de poder que existe entre la gente y los medios de comunicación (Arriagada y Navia, 2013, p.13).

\subsection{Tecnología, democracia y ciberactivismo}

El entusiasmo que varios autores (Norris, 1997; Davis, 1999; Graber, 2001; Di Maggio, 2004; Dahlgren, 2005; Fages-Ramió 2008; Resina, 2010) han visto en las posibilidades de las nuevas tecnologías radica en poder utilizarlas para contrarrestar la crisis de legitimidad, credibilidad y participación por la que atraviesan los sistemas democráticos. Ello queda en evidencia en las bajas tasas de participación electoral y en actitudes de mayor desconfi anza hacia partidos, parlamentarios y políticos. En mayor o menor medida, las críticas al ejercicio del poder son unánimes en las democracias occidentales. Diversos estudios con fuerte base empírica, demuestran la creciente insatisfacción por el funcionamiento de los sistemas políticos y la desafección de los ciudadanos hacia los actores e instituciones políticas de cada país (Norris, 2002; Montero et al, 2006).

Las nuevas tecnologías incorporan elementos a las formas tradicionales empleadas por organizaciones políticas con la intención de movilizar a las personas. Pareciera, analizando los sitios webs de parlamentarios chilenos, que ellos no toman conciencia de la democratización digital que se está viviendo. Internet permite que individuos no organizados lideren campañas masivas y exitosas (Peretti y Micheletti, 2004; Sampedro, 2005). Los nuevos movimientos sociales han sido pioneros en el uso de nuevas herramientas de la información y la comunicación, demostrando que las posibilidades de comunicación en red y de interacción continuada reducen los costes de la movilización (Della Porta y Mosca, 2005; Van Aelst y Walgrave, 2004; Geser, 2001). Así la facilidad con la que se crean las redes y la opción de agrupar colectivamente a personas con intereses comunes conectan el uso de nuevas tecnologías con la movilización (Garrett, 2006).

Internet y las redes sociales constituyen una plataforma segura que permite a los ciberactivistas comunicarse, organizarse y realizar las acciones necesarias para mantener viva la lucha social a nivel local, al margen de la censura oficial y de la vigilancia del Gobierno. El ciberactivismo 
permite visibilizar las carencias del país y hacer llegar las protestas y denuncias a foros internacionales, que es donde tienen más impacto y son más efectivas (Soengas \& Assif, 2017).

En definitiva, perseguir una sociedad más transparente y predispuesta a la rendición de cuentas de sus acciones y actuaciones, permite estimular una participación más activa de sus ciudadanos, de su tejido asociativo y, a la vez, tenderá los puentes necesarios para que las instituciones y organizaciones se acerquen a la ciudadanía (Baamonde, 2017).

\section{Métodos y técnicas de investigación}

Esta investigación se trazó como objetivo general analizar la eficacia de los sitios webs de los Diputados chilenos como herramienta comunicacional. Con este fin se establecieron los siguientes objetivos específicos A) Determinar los niveles de interacción existentes entre los Diputados y la ciudadanía a través de los sitios webs. B) Analizar el uso que los Diputados chilenos otorgan a los sitios webs como herramienta comunicacional C) Determinar qué estrategias de comunicación digital son utilizadas por los Diputados en sus páginas webs.

Esta investigación corresponde a un tipo de estudio exploratorio-descriptivo de acuerdo a la clasificación de Danhke (Salinas y Cárdenas, 2008) que utiliza como método un análisis de contenido diseñado específicamente para sitios webs (Dader, 2004, 2006, 2008, 2011) basado en una escala valorativa. Dicha escala valorativa fue aplicada a la totalidad de los sitios webs de los Diputados en ejercicio, período 2014-2018 en dos momentos distintos dada la cercanía de elecciones parlamentarias. El primero de ellos fue en octubre del 2015 y el segundo momento en enero del 2018. Totalizando 66 sitios webs de Diputados en ejercicio, analizados durante octubre del 2015 y 63 sitios en enero del 2018. Para el análisis, se utilizaron las cuatro grandes dimensiones propuestas por Dader que, a su vez, se inspira, originariamente en De Landtsheer (1999), adaptado a indicadores propios de la realidad chilena, por lo que se añadieron otras dimensiones fruto de la reflexión propia de los investigadores.

Así, a las dimensiones existentes (Información, Interactividad, Sencillez de uso y Atractivo) se agregó una nueva dimensión identificada como "Redes" que enriqueció y actualizó el instrumento. Tanto para las dimensiones como para sus indicadores dicha metodología fue complementada con algunos elementos de la propuesta metodológica de los autores ingleses Rachel Gubson y Stephen Ward, diseñada para el estudio de la función y eficacia de los websites de partidos y candidatos (Gibson y Ward, 2004).

Cada dimensión fue analizada a través de criterios específicos. Así la dimensión Información fue analizada por los criterios 1) Presentación y relaciones públicas, 2) Información externa, 3) Información de generalidades útiles, 4) Información política para los ciudadanos, 5) Información política de contexto y 6) Símbolos de propaganda política. La dimensión Interactividad fue analizada por los siguientes criterios 1) Posibilidad de lectura, 2) Lectura y respuesta a formularios, 3) Exposición de información que promueve el diálogo, 4) Posibilidades de auto-presentación. La dimensión Sencillez de Uso fue analizada por los siguientes criterios: 1) Actualización o puesta al día, 2) Condensación, 3) Ayuda para la búsqueda y la navegación. La dimensión Atractivo se analizó por los siguientes criterios: 1) Sentido del humor e ironía, 2) Imágenes y fotos, 3) Atractivo visual y diseño. La dimensión Redes, en tanto, fue analizada por 1) Convergencia con otros formatos, 2) Conexión con medios 
de comunicación, 3) Posibilidad de acceso de redes sociales, 4) Posibilidad de organizar actividades y 5) Flujo multidireccional.

La suma de las cinco dimensiones: Información, Interactividad, Sencillez de Uso, Atractivo y Redes, descritas anteriormente, permite alcanzar un total absoluto.

Cada una de las dimensiones principales comprende criterios que puntúan de acuerdo a la escala de Likert de la siguiente manera:

$$
\begin{aligned}
& 0 \text { puntos }=\text { El rasgo analizado nunca está presente } \\
& 1 \text { punto }=\text { El rasgo está presente raramente } \\
& 2 \text { puntos }=\text { El rasgo está presente ocasionalmente } \\
& 3 \text { puntos }=\text { El rasgo está presente frecuentemente } \\
& 4 \text { puntos }=\text { El rasgo está presente muy frecuentemente }
\end{aligned}
$$

Después de sumar, se obtienen los resultados para cada una de las categorías especificas o principales. La suma general de todas las dimensiones determina un indicador general de la eficacia del sitio web y de sus diferentes elementos. Al término del análisis anteriormente expuesto, se restablece una codificación que determina el nivel de eficacia de los sitios webs de los Diputados chilenos como herramienta comunicacional.

Tabla 1. Rangos de eficacia

\begin{tabular}{|c|l|c|}
\hline & \multicolumn{1}{|c|}{ Rango } & Valores \\
\hline 1 & Ineficaz & $0-20$ \\
\hline 2 & Mediamente ineficaz & $21-41$ \\
\hline 3 & Medianamente eficaz & $42-62$ \\
\hline 4 & Eficaz & $63-84$ \\
\hline
\end{tabular}

Fuente: Elaboración propia

En una última etapa de la investigación, los autores decidieron agregar datos que demuestran la presencia de los parlamentarios en perfiles de Facebook y Twitter. Dicha observación si bien se realizó en Julio del 2019 consideró el mes de enero del 2018, como una forma de analizar a los mismos parlamentarios en ejercicio cuyas webs son revisadas en el estudio. Las variables utilizadas son la presencia o no presencia del parlamentario en perfiles de Facebook y Twitter y la cantidad de post y twist respectivamente.

\section{Resultados}

Un primer dato es que la cantidad de sitios webs disminuye en número el 2018, respecto del 2015. Mientras el 2015 un 55\% del total de Diputados contaba con un sitio web, el 2018 baja a un 52,5\% de los Diputados. Asimismo, los Diputados sin sitio web pasan de un $45 \%$ a $47,5 \%$ en los años 2015, 2018, respectivamente. (Figura 1). 
Figura 1. Existencia de sitios webs de Diputados

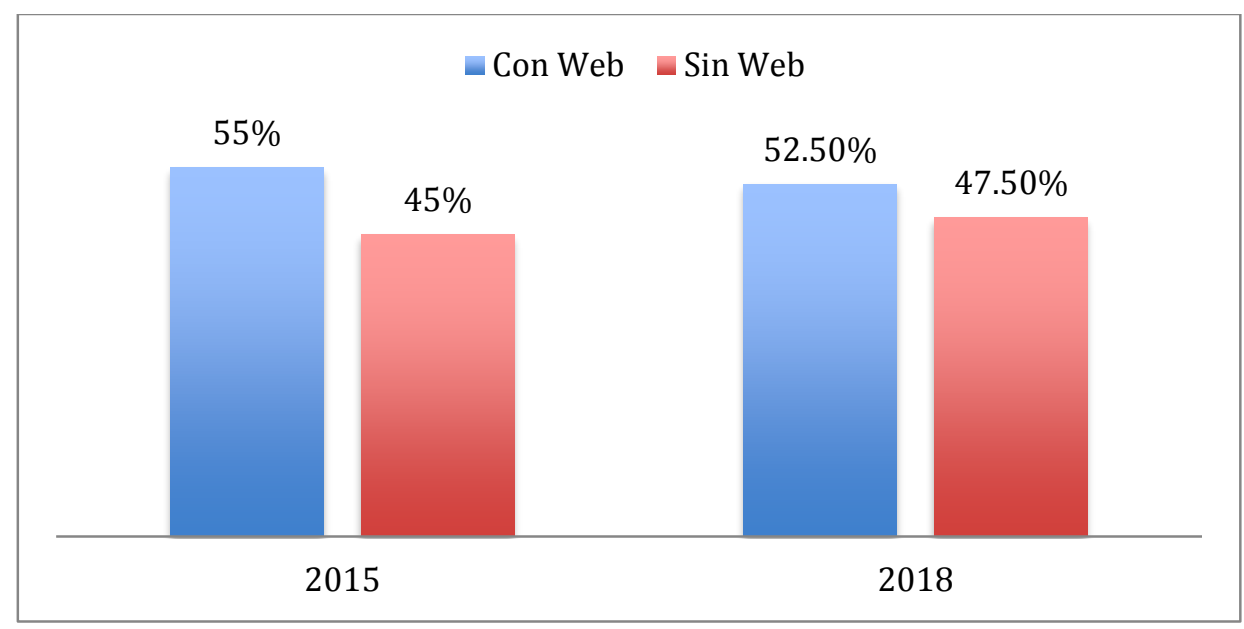

Fuente: Elaboración propia

Respecto a los indicadores de criterios, los resultados indican que ninguno de los sitios webs alcanza el nivel de eficacia propuesto en alguno de los momentos de observación, octubre del 2015 y enero del 2018. (Figura 2).

El porcentaje de sitios medianamente ineficaces es casi el mismo para el 2015 (Figura 2) y 2018, un $68,1 \%$ para el 2015 y un $68,2 \%$ para el 2018 . Sin embargo, existe diferencia a favor de los sitios medianamente eficaces el 2018, donde suben a un 20,6\% contrastando con el 16,6\% del 2015. Los sitios ineficaces en tanto bajan de un 15,1\% del universo el 2015 a sólo un $11,1 \%$ el 2018 (Figura 2).

Respecto a la dimensión "Información" uno de los criterios que mantiene su presencia es el de Auto-presentación y relaciones públicas. Sumados los indicadores de está presente frecuentemente y está presente muy frecuentemente el 2015 alcanza el 53\%, mientras que el 2018 el criterio suma un 58\% sumando los mismos indicadores. Ello evidencia que existe un alto porcentaje de Diputados que tiende a la auto presentación como una forma de darse a conocer al internauta, priorizando su marca política personal sin la identificación del conglomerado político.

En la misma dimensión "Información", en Información externa los datos enuncian que el criterio descrito nunca está presente. Esto confirma el escaso interés por parte del diputado por orientar a la ciudadanía en otros temas que no sea la noticia en la que participó el propio parlamentario, encapsulando sus acciones e incluso dando pie a expresiones de individualismo y megalomanía.

Continuando con la dimensión "Información”, en el criterio Información política para los ciudadanos, los resultados no son claros respecto de la presencia o ausencia del rasgo, siendo el porcentaje más alto el indicador está presente ocasionalmente con un $28 \%$ en ambos períodos 
Figura 2. Nivel de eficacia por momentos de observación

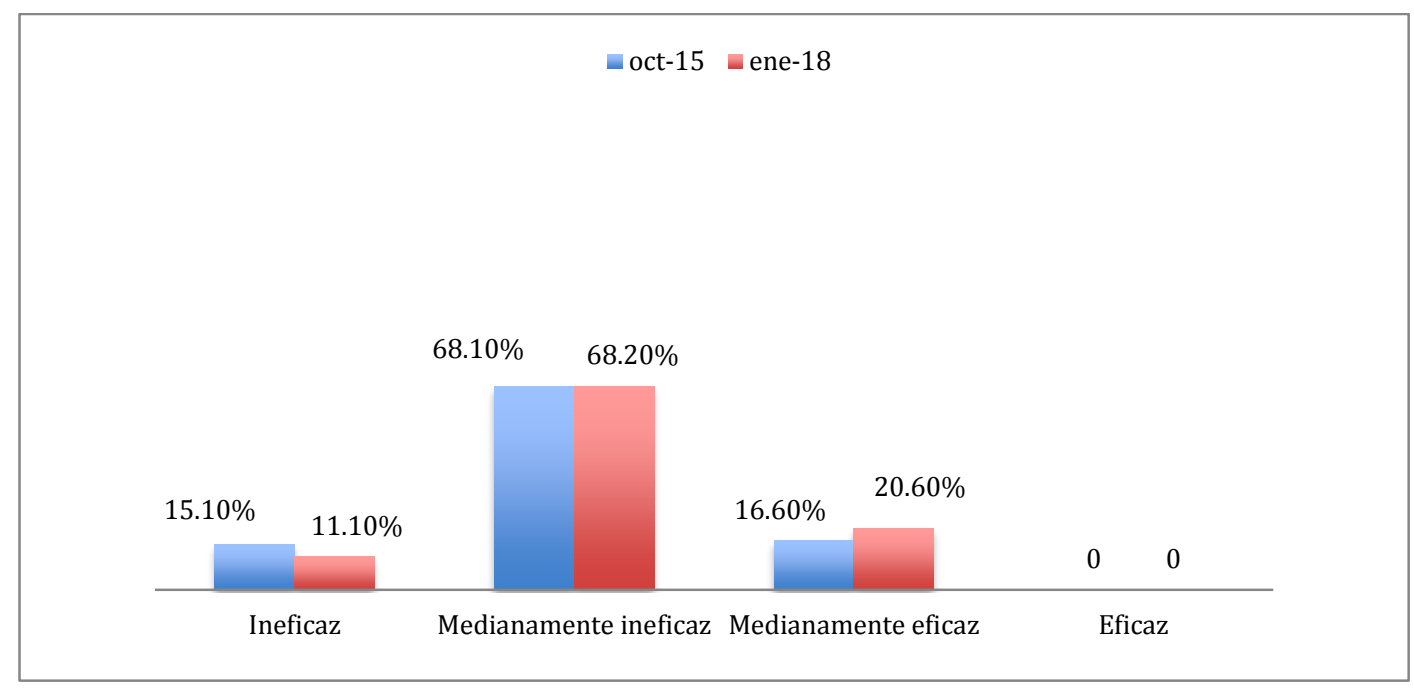

Fuente: Elaboración propia

Continuando con la dimensión "Información", en el criterio Información política para los ciudadanos, los resultados no son claros respecto de la presencia o ausencia del rasgo, siendo el porcentaje más alto el indicador está presente ocasionalmente con un $28 \%$ en ambos períodos.

Respecto a la información política de contexto definitivamente no está presente en ningún período de observación. El 2015 alcanza un 68,2\% y el 2018 un 70\% al sumar los indicadores nunca está presente y presente raramente. Esto indica la subutilización del sitio digital como herramienta de branding y posicionamiento de marca, sin la posibilidad de aportar información política y documentación de calidad que ayude al ciudadano a tomar decisiones de forma informada. Ya en el criterio de símbolos y propaganda política, los datos indican que el 2015 este rasgo nunca está presente en un 80\% de los sitios, mientras que en el 2018 las cifras alcanzan el 79\% sumando los nunca está presente y los presente raramente. Ello indica que los símbolos y propaganda del partido al que pertenece el parlamentario no figuran y menos se vinculan con la web del Diputado. Existe una tendencia clara por desvincularse del partido político en términos de branding, desmarcándose del mensaje del conglomerado y personificando el mensaje político en una persona y no en un bloque partidario.

En torno a la dimensión "Interactividad", la mayoría de los sitios sólo permiten la lectura y no admiten otro tipo de interactividad. Esto queda de manifiesto en ambos momentos de observación tanto el 2015 con un $62 \%$ y el 2018 con un $54 \%$, lo que provoca que el usuario no pueda comentar alguna noticia en la web y sólo se remita a leer. En esta dimensión de interactividad, el dato más clave es la no posibilidad de autopresentación por parte del usuario. El 2015 el 100\% de los sitios y el 2018 el 95\% de ellos no da la oportunidad a sus usuarios de presentarse a sí mismos. No existe la posibilidad de que los ciudadanos puedan comentar temas relevantes, tampoco enlazar otras páginas, en general, no es permitida la integración ni la interacción entre las partes.

Respecto a la dimensión "Sencillez de uso", la mayor parte de los sitios de los Diputados no incluyen el criterio de la ayuda o búsqueda de información. 62\% el 2015 y $59 \%$ el 2018. Por lo tanto, el facilitar el proceso de búsqueda de datos de interés ciudadano no es prioritario para los 
sitios webs. Respecto a la actualización de información, los datos no son tan claros, predominando el indicador presente ocasionalmente en ambos períodos de observación, con un $33,3 \%$ el 2015 y un $27 \%$ el 2018. También hay una buena evaluación para el criterio condensación de información en esta dimensión, lo que potencialmente facilita la lectura del sitio, con un $57,6 \%$ el 2015 y un $58 \%$ el 2018 sumados los presentes frecuentemente y muy frecuentemente presentes.

Ya en la dimensión "Atractivo" de los sitios, el criterio sentido de humor y la ironía no están presentes definitivamente. Un 100\% el 2015 y un 98\% el 2018 nunca está presente el criterio, lo que indica que los sitios webs de Diputados chilenos se caracterizan por su estilo solemne, sin innovación en el tratamiento, ni pretenden acudir a este tipo de recursos para enlazar con el ciudadano. Respecto al criterio Imágenes y fotografías, la dimensión debe considerar que las imágenes y fotos expuestas en los sitios webs en general, son cuantiosas, sin embargo, la medición estipula que, si las imágenes y/o fotografías presentadas sólo incluían al parlamentario en cuestión, no sería bien evaluado; dicha situación es recurrente en un $62 \%$ de los casos analizados el 2015 y en un $67 \%$ el 2018.

De ahí que la mayoría de los sitios webs examinados presenta fotografías únicamente del diputado a quien pertenece dicha página. No integrando la imagen marca del Diputado con la ciudadanía. Ya respecto al criterio atractivo visual y estructura, se nota una preocupación por la estética del sitio en un grado medio, es decir presente ocasionalmente, lo que habla de la escasa uniformidad de los sitios, pero también del poco esfuerzo por figurar con una página cautivadora o que presente rasgos innovadores en su diseño. Esto es importante de considerar, pues no existe un interés claro de innovar en el diseño y estructura como una forma de marcar diferencias respecto a los otros Diputados.

En torno a la dimensión "Redes", el criterio Convergencia el 2015 alcanza un 51,5\% y el 2018 un $50 \%$ los sitios que se preocuparon de tener otros formatos en sus plataformas, entiéndase video o audio, sumados los presentes frecuentemente y muy frecuentemente presentes. En ese sentido, no hay una preocupación mayoritaria por virilizar contenido en la red a través de la convergencia de formatos. Respecto al criterio conexión con otros medios de comunicación, una gran mayoría de los sitios no cuenta con ningún enlace a medios de comunicación, de hecho, el 2015 un 78,8 \% de los sitios no tenía link a medios de comunicación, mientras que el 2018 la ausencia de dicho criterio sube al $83 \%$. El porcentaje logrado muestra la tendencia irrefutable de la personalización y el encapsulamiento de la política en Chile, exponiendo una desconexión del mundo político y/o comunicacional a través de sus sitios webs.

En la misma dimensión, pero en el criterio Redes Sociales, los datos indican que el 2015 un $87,9 \%$ de los sitios webs indagados las utilizan, sumado la opción del presente frecuentemente y presente muy frecuentemente, mientras que el 2018 un $92 \%$ de ellos las incluyen en sus contenidos. Es importante señalar que el hecho que el acceso a redes sociales esté disponible, no significa -necesariamente- que puedan mantener comunicación directa con el diputado/a en cuestión. El uso que hacen los Diputados de sus sitios webs merma la posibilidad de democratizar/ceder poder a los ciudadanos, es decir, no permite que éstos puedan aportar/incidir en la construcción de agenda pública, como podría lograrse por medio de la participación a través de redes sociales. También en la dimensión Redes, pero en el criterio posibilidad de organizar actividades (por parte de los usuarios), un 98,5\% de los sitios estudiados el 2015 e 
igual porcentaje el 2018 nunca lo incluyen dentro de las posibilidades de interacción para los ciudadanos, marginándolos del proceso de construcción comunicacional bidireccional.

Similar situación ocurre con el criterio flujo multidireccional de los sitios webs analizados. El 2015 un 97\% de ellos carecía de esta condición, mientras que el 2018 un 90\% de ellos no incluía el recurso en sus contenidos, cuestión que reafirma la tendencia mostrada hasta el momento respecto de la escasa preocupación de los parlamentarios por utilizar los sitios webs como espacios que convocan y generan interacción entre los diversos actores.

Si bien no es uno de los objetos de investigación de este artículo, vale la pena detenerse a observar cómo ha sido el comportamiento de interactividad de los 120 Diputados chilenos analizados en relación al uso de las dos redes sociales más populares como son Facebook y Twitter. Dichos datos pueden servir para potenciar futuras investigaciones al respecto en torno a la relación existente entre redes sociales y política y también para comparar el uso de dichas plataformas en concordancia con el uso de sus webs, dando así una mirada más amplia a esta investigación. La observación de dichas plataformas sociales si bien se hizo en julio del 2019, se centró en analizar el mes de enero del 2018 para coincidir con los Diputados cuyos sitios webs fueron objeto de investigación y también para anticiparse a la renovación del Parlamento ocurrida en marzo del 2018 que vino a modificar la Cámara tanto en número, de 120 a 155, como en nombres de Diputados.

En el caso de la red social Facebook de los 120 Diputados en ejercicio durante el mes de análisis, 104 parlamentarios lo ocupan, lo que equivale a un $86,6 \%$ del total de la cámara. Totalizando 1 mil 287 post durante todo el mes, lo que anota un promedio de 12 post por diputado mensuales, es decir un post cada 2,5 días.

En el caso de la red social Twitter, creada en el 2006, son 99 los parlamentarios que poseen Twitter durante enero del 2018, lo que equivale a un $82,5 \%$ del total de la Cámara. Totalizando 4 mil 658 tweets durante todo el mes, lo que anota un promedio de 47 tweets por Diputado mensuales, es decir un tweet cada 1,5 días.

Considerando lo anterior cabe señalar que, si bien existe un alto porcentaje de adopción de dichas plataformas, no se observa una sinergia con las otras herramientas digitales de los Diputados ni una planificación estratégica coherente entre los distintos soportes comunicacionales. El modelo de "muchos a muchos" propio de la sociedad red (Castells, 2009) tampoco se ve representando en el uso de las redes sociales, manteniendo el esquema unidireccional del antiguo paradigma de la comunicación de masas.

Asimismo, el uso de las redes tanto de Facebook como de twitter, está asociado a un nivel exclusivamente informativo sin la invitación a interactuar para convertirse en un nodo eficiente como propone la Teoría de Redes.

\section{Conclusiones.}

La irrupción de las Tics en política no ha sido ni es sinónimo de una democracia directa, pero sí podría representar una esperanza en cuanto a las posibilidades de transparencia por parte de la clase política, interacción con sus votantes y participación del ciudadano que en definitiva se puede traducir en mayor democracia. 
Un promedio del 50\% de los Diputados chilenos, en ambos momentos de observación, cuenta con sitio web. A pesar que Internet brinda la posibilidad de desarrollar diversos mecanismos de comunicación, los sitios webs de políticos analizados muestra un evidente retraso en la utilización de estas posibilidades como herramientas de branding digital. De hecho, gran parte de la información del sitio web del parlamentario es utilizada de manera unidireccional y de forma similar a los tradicionales medios de comunicación como la tv, radios y periódicos. Se evidencia entonces una manera de expresión vertical de información política, pero en formato digital. No se distingue una estrategia digital tendiente a crear una comunicación multidireccional con el internauta y posible votante. Por lo tanto, el Diputado sigue siendo una persona lejana para el público con un alto grado de dificultad de poder acceder a él.

La dimensión de "Información" revela que la mayoría de los parlamentarios no entrega datos que permitan a la ciudadanía conectar con ellos, comprobándose el encapsulamiento de los Diputados de Chile que se alejan de la dinámica de relacionamiento propia de la sociedad red propuesta por Castells (2001 y 2009). Dicha situación, se visiona también en el criterio de "información general" que indica que éstos impiden generar instancias de accesibilidad y acercamiento con los ciudadanos. Esto es contrario a lo impulsado ya hace 20 años por Bartels y replicado por Vila-López (2013), donde se hace necesaria la presencia de información respecto a temas que le sean próximos a los electores: familia, educación, seguridad, vacaciones, como una manera de hacer más cercana la "marca" del Diputado a la ciudadanía. Ante la ausencia de links a especialistas, a documentación, a videos que toquen temas cercanos a la gente, se observa un temor en la estrategia por perder al internauta en otros temas ajenos a la figura del Diputado, siendo que el efecto es muy favorable para "la marca", pues se asocia como una forma de consejo positivo del diputado frente a temas que le son importantes al usuario y que determinan un mejor posicionamiento del político en la mente del elector.

Respecto de los resultados de la dimensión" Interactividad", la idea de posibilidad única de lectura demuestra que existe una manera de expresión vertical de información desde los políticos a la ciudadanía, transformando la web en una especie de panfleto personalizado, sin posibilidad de interacción para el ciudadano. Cuestión que se acrecienta con los criterios de "lectura y sólo respuesta a formularios" y la total ausencia del criterio "exposición de información que promueve el diálogo", demostrando que los sitios webs no consideran la participación activa de los votantes, ni tampoco promueven, incitan o propician condiciones para el intercambio de información. De esta forma, los sitios webs son más bien espacios de difusión de mensajes y contenidos sobre sus actividades, más que una vía para establecer debates y discusiones colectivas, destinadas a influenciar el proceso de elaboración de políticas públicas y de toma de decisiones, según plantean autores como Davis, Norris, y otros (1999). Ello impide, como dice Larrondo, el fortalecimiento de un tejido social más comprometido y por supuesto la consolidación de una estrategia digital a través de las herramientas digitales que potencialmente tiene un sitio web. De esta manera, los sitios webs son desaprovechados como herramienta comunicacional especialmente por la falta de una estrategia digital que busque consolidar al diputado en una o algunas áreas específicas de interés social, según sea la propia naturaleza profesional del diputado, la circunscripción que representa o la experiencia parlamentaria en comisiones específicas de la Cámara.

La dimensión "Sencillez de uso" es relevante dado que los resultados indican que los políticos chilenos no hacen utilización de las bondades de la comunicación política, dado que no 
transmiten mucha información; la velocidad y la actualización no es permanente ni acorde a las posibilidades propias de esta herramienta virtual, ni tampoco enlazan con otras fuentes de información, por lo que la entrega de información sigue siendo centralizada.

Con la dimensión "Atractivo" del sitio web, al igual que otras dimensiones anteriores, no se logra utilizar a cabalidad un mecanismo altamente creativo capaz de conectar y persuadir a públicos cada día mucho más exigentes e informados. Criterios como el humor o elementos visuales relevantes, como animaciones, cápsulas o secuencias de imágenes están ausentes en la gran mayoría de los sitios analizados. Ello adquiere más relevancia cuando la sociedad en red tiene como característica la posibilidad de viralizar otros formatos, no necesariamente el escrito, cuestión que aporta a la masificación de la información. Según algunos autores, el poder de la imagen es muy utilizado en la comunicación política, creando una especie de sociedad teledirigida que permite "facilitar" el trabajo de interpretación del ciudadano, entregando el mensaje "envasado".

Finalmente, la dimensión de "Redes" muestra que no existe preocupación por transformar a la web en una herramienta comunicacional interactiva que facilite el contacto con los ciudadanos. A pesar que el valor del sitio web -desde el punto de vista de las redes- está en la posibilidad de constituirse como un nodo, eso definitivamente no se logra. En general, es una muestra de comunicación de tipo jerárquica, entre políticos y ciudadanía, considerados éstos últimos como pasivos desde el punto de vista del emisor del mensaje. Parece ser una constante en el mundo político analizado que las "bondades de la comunicación política" no son utilizadas en todo su potencial, los Diputados pierden la oportunidad de generar este tipo de relaciones, que, dado el alto nivel de avance de las comunicaciones digitales, debería estar en un alto nivel de retroalimentación. De este punto de vista, el diputado se muestra como inalcanzable para el común de la población y no como un líder de opinión que "escuche" a sus potenciales electores.

Por último, los resultados respecto del criterio "flujo multidireccional" que también puntúa a la Dimensión "Redes" muestra que en la mayoría de los sitios webs de Diputados chilenos, persiste el paradigma de la comunicación de masas, a pesar de las múltiples tendencias que indican que éste ha sido reemplazado por la auto comunicación de masas. A todas luces, la comunicación política no es entendida como la etapa en que los protagonistas del proceso comunicativo (gobernantes - ciudadanos) deberían relacionarse desde un equilibrio de poder distinto, por medio del flujo comunicacional multidireccional y multimodal. Todas ellas alternativas que pueden ser incluidas en un sitio web, por tanto, en la práctica, no es posible hablar de un nuevo paradigma. La comunicación sigue fluyendo de un emisor a una audiencia, que dadas las posibilidades tecnológicas pudiese eventualmente no ser anónima ni dispersa.

De acuerdo a los puntajes obtenidos en las distintas dimensiones analizadas se desprende que los sitios webs de los Diputados chilenos como herramienta comunicacional son medianamente ineficaces, promediando 28 puntos el 2015 y 34 puntos el 2018, de un máximo total de 84 que los catalogaría como sitios eficaces. Esto se torna importante de concluir si dichos datos se analizan a la luz de los indicadores de uso de las tecnologías de la información en Latinoamérica, que alzan a Chile como uno de los países con más altos índices en este sentido (Informe Subtel 2017). Así entonces, los sitios webs de parlamentarios están subutilizando el potencial informativo, dialogante y participativo de esta herramienta que pudiera realmente posicionar al candidato entre los electores. También se puede concluir que si bien no existe una estrategia de comunicación digital que busque potenciar la imagen comunicacional de cada político, existe 
conciencia que los sitios webs pueden constituir una buena herramienta comunicacional respecto de la imagen y quehacer del parlamentario candidato. Esto explica que surgieran 18 sitios webs nuevos en forma previa a las elecciones de diciembre del 2017, como una forma de dar a conocer quién es el diputado, cuál ha sido su labor y promover su candidatura. Sin embargo, la subutilización de la herramienta virtual y el desconocimiento de las potencialidades de la información política en una web, más que acercar a sus electores, muchas veces desconciertan al ciudadano, afectando la imagen del diputado.

A diferencia de lo que ocurre en otros espacios como los medios de comunicación o la publicidad donde se ha generado la integración digital, en la Cámara de Diputados no se observa una estrategia global de unificación de soportes. Los contenidos estáticos tanto de los sitios webs como de las redes sociales, que además no sintonizan entre sí, desaprovecha las ventajas de la tecnología como una herramienta eficaz de comunicación política.

A la luz de los resultados es claro que el uso que hacen los Diputados de sus sitios webs y de las plataformas sociales merma la posibilidad de ceder poder a los ciudadanos y no permite que éstos aporten o incidan en la construcción de agenda pública, consiguiendo sólo que los espacios públicos propios de la comunicación política se amplíen. Ello atenta contra la imagen parlamentaria en general y contra la marca del diputado en particular. Un parlamentario con una web idónea en términos de comunicar eficazmente, aportaría no sólo a posicionar al diputado en la mente de sus electores e internautas en un área específica, sino también a disminuir el flujo unidireccional en la comunicación político-ciudadano. Se concluye por tanto que los sitios webs de los Diputados chilenos necesitan ser repensados estratégicamente en términos de comunicación digital, pues actualmente están siendo utilizados en la lógica antigua y desfasada de la comunicación de masas y público pasivo, contradiciendo la participación ciudadana y la democratización digital que caracteriza al Chile del siglo XXI.

\section{Bibliografía}

Achor, N., Nwachukwu P. \& Udensi, M. (2017). Political Branding/Brand Personality and Voters' Choice of Candidate: An Empirical Inquiry into 2015 Presidential Election in Nigeria. Journal of Marketing and Consumer Research, vol. (37), 2017. Disponible en: http://iiste.org/Journals/index.php/JMCR/article/view/38058.

Arriagada A., Navia P. (Ed.) (2013). Intermedios Medios de comunicación y democracia en Chile. Santiago, Chile: Ediciones Universidad Diego Portales.

Baamonde, X. (2017). Las redes sociales como herramientas de relaciones públicas de las instituciones europeas. Correspondencias \& análisis, [S.1.], vol.1, p. 67-82. Disponible en: http://ojs.correspondenciasyanalisis.com/index.php/cya/article/view/93

Ballesteros, C., Zamora, R., Sánchez, P., \& Gil, A. (2017). La personalización de las campañas electorales online. Las elecciones generales de 2015 (20D) a través de Facebook. Paper Memorias del XXIII Congreso de la Sociedad Española de Periodística. Universidad Miguel Hernández, Elche.

Caro, A. (2010). Comprender la Publicidad. Barcelona, España: Editorial Extensiones de Facultat de Comunicació Blanquerna. Universitat Ramón Llul. 
Eficacia de los sitios webs como herramienta comunicacional de los Diputados chilenos.

Cardenas, A., Ballesteros, C., \& Jara, R. (2017). Redes sociais e campanhas eleitorais na América Latina. Uma análise comparativa dos casos de Espanha, México e Chile. Cuadernos.info, (41), 19-40. https://dx.doi.org/10.7764/cdi.41.1259

Castells, M. (2009). Comunicación y poder. Madrid: Editorial Alianza.

Dader, J. (2001). La ciberdemocracia posible: Reflexión prospectiva a partir de la experiencia en España. CIC Cuadernos de información y comunicación. Vol. 6, pp. 177-219.

Dader, J. (2003). Ciberdemocracia y ciberparlamento: El uso del correo electrónico entre los parlamentarios españoles y los ciudadanos comunes (1999-2001). TELOS. Cuadernos de Comunicación, Tecnología y Sociedad, vol.55. Abril-junio.

Dader, J. (2008). El derecho de acceso a la información pública en España: Una víctima de la sensibilidad políticamente correcta. En Sánchez de Diedo, M. (ED), El derecho de acceso a la información púbica (pp.135-152). Madrid: Fac CC Información CERSA.

Dader, J. y Cheng, L. (2011). Análisis cuantitativo y cualitativo de las webs de partidos. En Sampedro, V. (ED), Cibercampaña. Cauces y diques para la participación. Las Elecciones Generales de 2008 y su proyección tecnopolítica. Madrid: Editorial Complutense, pp. 130-143.

Dahlgren, P. (2005). The Internet, Public Spheres, and Political Communication: Dispersion and Deliberation, Political Communication, año 22 vol. 2, pp.147 - 162.

Davis, R. (1999). The web of politics. The internet's impact on the American Political System. New York: Oxford University Press.

De Landtsheer, C., Krasnoboka, N., \& Neuner, C. (1999). La facilidad de utilización de los web site de partidos políticos. Estudio de algunos países de Europa del Este y Occidental. Disponible en: http://www.revistas.ucm.es/index.php/CIYC/article/dowland/CIYC0101110107A/7359

Della P., Mosca D. y Mosca L. (2005). Transnational protest and global activism. New York Rowman and littlefield. Journal of Public Polici, vol. 25, pp. 165-190.

Fages-Ramió, R. (2008). Actitud 2.0: la política más allá de los blogs. IDP. Revista de Internet, Derecho y Política, vol. 7, pp. 19-25.

Garrett, K. (2006). Protest in an information society: a review of literature on social movements and New ICTs . Information, Communication\& Society, vol.9, (2). Disponible en: https://doi.org/10.1080/13691180600630773

Geser, H. (2001). On the functions and consequences of the internet for social movements and voluntary association social movements. Switzerland: Assoiations and political parties.

Gibson, R., Römmele A. \& Ward, S. (2004). Electronic democracy. Mobilization, Organization and participation Via New ICTs. London and New York: Editorial Routledge.

Grau, B. (2016). Activismo y Prácticas Digitales en la Construcción de una Esfera LGTB en España. Dados, vol. 59, n.3, pp.755-787. http://dx.doi.org/10.1590/00115258201691.

Montero, J., Font, J., \& Torcal, M. (2006). Ciudadanos, asociaciones y participación en España. Madrid España: Centro de Investigaciones Sociológicas, CIS. 
Muniz, C., Dader, J., Tellez, N. y Salazar, A. (2016). ¿Están los políticos políticamente comprometidos?: Análisis del compromiso político 2.0 desarrollado por los candidatos a través de Facebook. Cuadernos info, vol. 39, pp.135-150. http://dx.doi.org/10.7764/cdi.39.970

Norris, P. (1997). Women, Media and Politicis. New York: Oxford University press.

Peretti, J., \& Micheletti, M. (2003). The nike sweatshop email: political consumerism, internet and culture jamming. En M. Michelletti, A., Follesdal y Sotlle D. (ED). Politics, products and markets. Exploring political consumerism past and presente. (pp.127-144). New Jersey. Transaction Publisher.

Pérez Díaz, P. (2010). Reseña de "El candidato marca: Cómo gestionar la imagen del líder político" de Rocío Zamora Medina (coord.). Sphera Pública. Recuperado de: http://www.uacm.kirj.redalyc.redalyc.org/articulo.oa?id=29719345017

Resina de la Fuente, J. (2010). Ciberpolítica, redes sociales y nuevas movilizaciones en España: el impacto digital en los procesos de deliberación y participación ciudadana. Mediaciones Sociales, vol. 7, pp 143 - 164. doi:10.5209/rev_MESO.2010.n7.22284

Sampedro, V. (2005). 13M: Multitudes Online. Madrid: Libros de la Catarata.

Salinas, P. \& Cárdenas, M. (2008). Métodos de Investigación Social. Quito Ecuador: Editorial Quipus. Ciespal.

Soengas, X. \& Assif, M. (2017). Cyberactivisim in the Process of Political and Social Change in Arab Countries. Comunicar, vol.53, pp. 49-57. https://doi.org/10.3916/C53-2017-05

Sola-Morales, V., y Hernández-Santaolalla (2017). Abstención política y nuevas formas de participación política de los jóvenes: Análisis comparativo entre Chile y España. Revista Latina de Comunicación Social, vol. 72, pp. 629 - 648. Disponible en: http://www.revistalatinacs.org/072paper/1183/33es.html

Uribe, R., Buzeta, C. \& Reyes, J. (2017). Personalidad de marca de los partidos políticos en Chile: una mirada desde los ciudadanos más jóvenes. Cuadernos.info, vol. 41, pp. 89104. https://dx.doi.org/10.7764/cdi.41.1252

Van Aelst, P. \& Walgrave, S. (2004). Limitations and posibilities of the transnational mobilization: the case of E.U. Summit in Brussels.

Vila- López N., Aldas-Manzano J. \& Amoros-Kern E. (2013). Posicionamiento de marcas políticas a través de la web. Revista de Globalización, Competitividad y Gobernalidad, vol. 7, pp. 16-29. https://doi.org/10.3232/GCG.2013.V7.N1.01

Williams, Ch. \& Gulati, G. (2010). Communicating with Constituents in 140 Characters or Less. Working Papers. Paper 43. Recuperado de http://opensiuc.lib.siu.edu/pn_wp/43.

Williams, Christine B. (2017). Introduction: Social Media, Political Marketing and the 2016 U.S. Election. Journal of Political Marketing, vol. 16, pp. 207-211. DOI: $10.1080 / 15377857.2017 .1345828$ 